\title{
Narrative Approach for Identifying Movements of Change and the Value of Therapeutic Writing Related to Chronic Pain Management
}

\author{
Elin Dysvik ${ }^{1}$, Jorunn Drageset ${ }^{2,3}$, Bodil Furnes ${ }^{1}$ \\ ${ }^{1}$ Department of Health Studies, Faculty of Social Sciences, University of Stavanger, Stavanger, Norway \\ ${ }^{2}$ Faculty of Health and Social Sciences, Bergen University College, Bergen, Norway \\ ${ }^{3}$ Department of Public Health and Primary Health Care, University of Bergen, Bergen, Norway \\ Email: *elin.dysvik@uis.no
}

How to cite this paper: Dysvik, E., Drageset, J. and Furnes, B. (2016) Narrative Approach for Identifying Movements of Change and the Value of Therapeutic Writing Related to Chronic Pain Management. Open Journal of Nursing, 6, 1052-1063.

http://dx.doi.org/10.4236/ojn.2016.612100

Received: October 28, 2016

Accepted: December 27, 2016

Published: December 30, 2016

Copyright $\odot 2016$ by authors and Scientific Research Publishing Inc. This work is licensed under the Creative Commons Attribution International License (CC BY 4.0).

http://creativecommons.org/licenses/by/4.0/

\section{(c) (i) Open Access}

\begin{abstract}
In this study, we examined extensive narratives prepared by participants who attended a chronic pain management programme where therapeutic writing was included. The aim was to explore how narrators experience the contexts in which their lives unfold following a cognitive behavioural programme. The analysis was based on a three-sphere model for context analysis, which referred to the contexts in which the narrators located their life stories: their immediate inter-subjective relationships, the collective social field, and broad cultural meaning. We identified important change processes related to adaptation. Our examination of the experience of therapeutic writing clearly indicated that therapeutic writing is helpful. We suggest that obtaining a better understanding of living with chronic pain through storytelling as part of therapeutic writing and using a three-sphere model for context analysis could improve understanding and approaches to nursing. Health carers should organize care around the experience of illness and its inter-subjective, social, and cultural consequences, which may provide a deeper understanding of identity and the core themes embedded in life stories.
\end{abstract}

\section{Keywords}

Chronic Pain Management, Context Analysis, Narrative, Movements of Change, Therapeutic Writing

\section{Introduction}

Chronic pain demands lifelong coping because of health challenges and an unforeseen life course, which may lead to changes in peoples' ideas about themselves as they move 
between different social identities, and some may seem to lose themselves [1]. In this study, we investigated the experiences of women who found themselves in this situation because they had suffered from chronic pain for a long period of time. These women had received several treatments and as their situation worsened, they were offered a pain management programme based on cognitive behavioural therapy (CBT). Their experiences were described as narratives that contained different stories and perspectives regarding their life situation. These written narratives may be described as a set of signs built from elements that convey meaning [2].

In health research, illness narratives are recognized increasingly as legitimate data sources as they may capture individual suffering in everyday life and yield insights unobtainable by other means [3]. In narrative terms, the threads of a person's life may become broken during illness and they must be reconnected in some way. Thus, telling new stories by reconstructing and revising previous stories may provide an opportunity to link the broken threads of one's life. This involves obtaining an understanding of the illness, but also past and future perspectives [2]. To understand the patient's perspective and health care needs, the health care worker must capture the patient's explanatory model, which refers to the concepts held by patients regarding their illness and life circumstances. Their explanations are often tacit and they may contain contradictions and shifts in content. Furthermore, these models are connected to strong emotions, which are difficult to express openly [2]. Promoting hope is essential in chronic illness. As a result of therapy, patients should achieve a degree of distance from their earlier emotional state. To achieve success, health carers must organize care around the experience of illness and its social and cultural consequences [4].

\subsection{Context and Therapeutic Writing}

Therapeutic writing may be defined as expressive and reflective writing by patients, which can be self-generated or suggested by a therapist or researcher. Therapeutic writing is of great value during illness because it includes personal, explorative, and expressive writing [5]. It is a personal and informal form of writing, which can give rise to uncensored and direct writing. This form of expressive writing is close to inner speech and thought processes, and it may be considered an introspective technique for discovering one's own thoughts and feelings [5]. This type of writing may also be described as a therapeutic tool because it may lead to reflection about the writer's life experiences [6] [7].

Several researchers have documented the positive effects of writing as an aid for adjusting to challenging life situations [8] [9] [10] [11] [12]. Previous findings indicate that therapeutic writing may strengthen $\mathrm{CBT}$ by facilitating cognitive restructuring processes in chronic pain [13]. Additional insights may be gained into chronic pain by using a narrative approach [1].

While writing interventions have proven to be useful in a variety of life situations, more studies seems needed to examine the utility of therapeutic writing following a CBT programme for chronic pain. Chronic pain is a subjective experience that occurs 
in a specific person and situation, so chronic pain is influenced by context [14]. Zilber et al. [15] indicated that individual identities are bound by context because people construct their stories within a social relational framework and in terms of the culture to which they belong. However, despite the consensus among narrative researchers about the importance of referring to the context when analysing narratives, the importance of context remains unclear [16].

\subsection{Aim and Research Question}

Based on the considerations outlined above, the aim of the present study was to explore how narrators experience the contexts in which their lives unfold following a CBT programme.

Two research questions were addressed, as follows.

How can we identify movements of change related to contextual conditions?

What is the value of therapeutic writing within contexts?

\section{Methods}

\subsection{Participants and Intervention}

Three women who attended an eight-week group-based pain management programme in spring 2014 participated in this study. They met the following inclusion criteria: age between 18 - 67 years; chronic non-malignant pain lasting for longer than six months; medical investigation and/or treatment completed before referral; motivated to participate in an active rehabilitation programme and no ongoing litigation due to their pain problem. The group participating in that programme comprised 13 members, of whom four were men. The mean age of the group members was 49 years. They all reported severe pain problems, and for our participants, pain was related to several body regions.

The overall focus of the eight-week CBT programme was to highlight how maladaptive feelings and thoughts may influence the perception of pain [13]. Therapeutic writing was included as a tool related to homework tasks (Table 1). Guidelines for writing were introduced and delivered (Appendix 1) together with four different writing tasks in the first meeting (Appendix 2). They could also choose to write about personal topics, and about whatever they felt was important for them to explore and express. The intention was that this material would belong to the participant.

\subsection{Data Collection and Materials}

The group leaders gathered the data. Three self-selected participants willingly and anonymously gave their stories written as part of the CBT programme to the group leaders as a way of demonstrating a new start in life. These narrators gave permission for the researchers to use their written narratives in ongoing research. Informed consent was obtained. The empirical materials comprised 31 rich and detailed handwritten pages. The guidelines for the writing tasks were followed strictly to frame their narratives. Different stories and perspectives were obtained and the content often shifted. The writing style varied from highly structured with accurate spelling to a more spon- 
Table 1. A chronic pain management programme: organization of the sessions and corresponding topics covered in the programme.

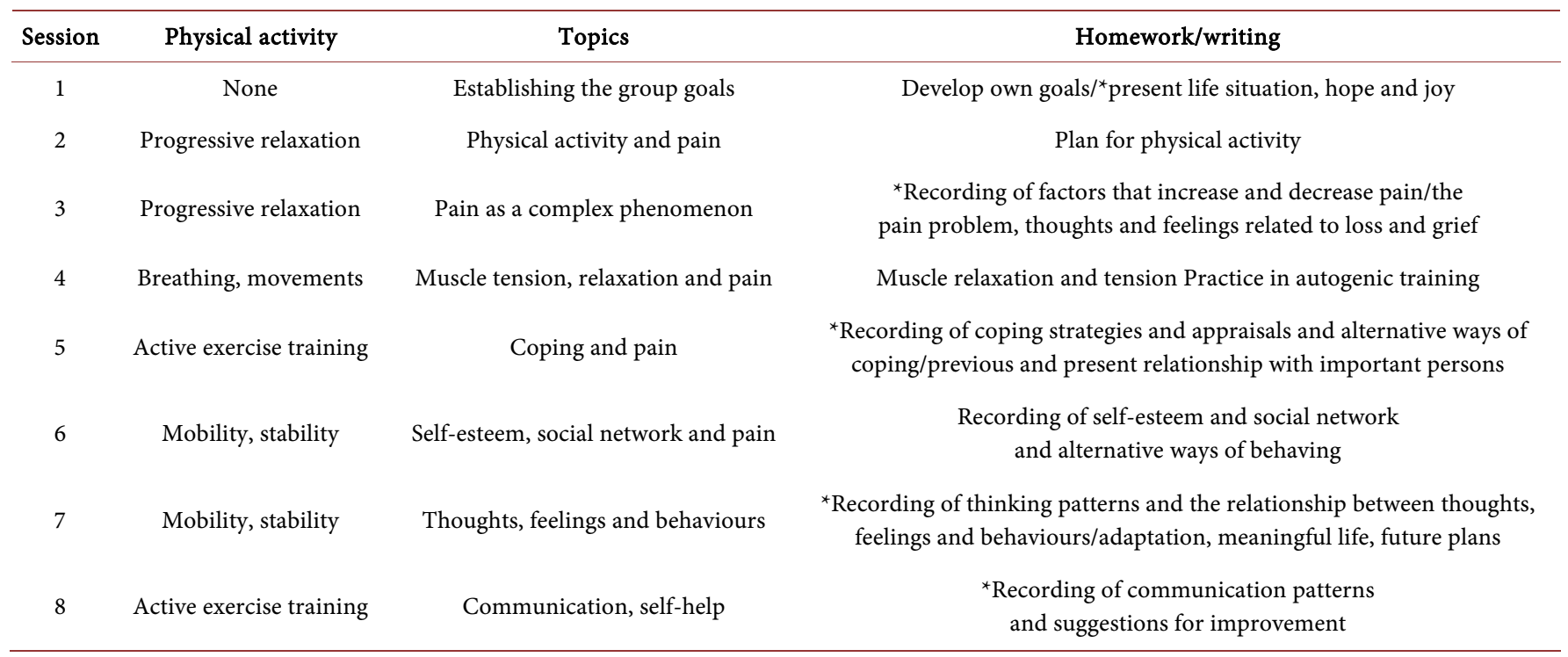

*Topics for therapeutic writing undertaken.

taneous and expressive style with deletions, exclamation marks, and underlining, with shifts in context. Several metaphors and turning points were identified. The study was approved by the Regional Committee and the Data Inspectorate (Ethical approval no. 428.10).

\section{Analysis}

A model for context analysis was selected, which referred to three distinct contexts where life stories could be situated, thereby providing a tool for understanding the motivations, values, and meaning systems that are important for constructing identity [16]. These contexts comprised inter-subjective relationships, the collective social field, and broad cultural meaning. The focus was on understanding the identity of the narrators and the choices shaped by the contexts in which they live [15] [16]. We performed a systematic exploration of the text context, where there was some flexibility in its reading and interpretation. The data analysis comprised the following six stages.

1. Transcription of the hand-written material.

2. Reading the text several times to obtain an overall sense of the whole text.

3. Highlighting exclamation marks, underlining, and metaphors.

4. Performing context analysis (Table 2).

5. Searching for turning points and therapeutic writing elements in different contexts.

6. Reflection and discussion, and selecting quotes.

\section{Findings}

The lives of those who attended the course were filled with pain and a vicious circle was identified, which involved loss of sleep, inactivity, uncertainty, hopelessness, and addi- 
Table 2. Examples of three spares of context.

\begin{tabular}{ccc}
$\begin{array}{c}\text { The immediate inter subjective } \\
\text { relationships in which the narrative is produced }\end{array}$ & $\begin{array}{c}\text { The collective social field in which } \\
\text { one's life story evolves }\end{array}$ & $\begin{array}{c}\text { The broad cultural meaning systems that } \\
\text { underlie and give sense to the particular story }\end{array}$ \\
\hline $\begin{array}{l}\text { The present situation: Help seeking, } \\
\text { at home mostly, periodically in bed, } \\
\text { lack of energy, outside daily pulsating life }\end{array}$ & $\begin{array}{c}\text { The family: spouse/partner, } \\
\text { children, parents, grandparents }\end{array}$ & Self-realization in a modern society \\
Friting is related to topics in a CBT programme & Group leaders and members & Colleagues \\
& Health care workers & Laws and regulations during illness \\
Employees in NAV & Health care system
\end{tabular}

${ }^{*} \mathrm{NAV}$ : Common agency for employment, social security and social services [17].

tional health problems. At the end of the course, their life situation assessments clearly indicated movements of change towards a stronger identity because hopes and future perspectives were outlined.

\subsection{Narratives and Contexts}

The narratives were situated in a help-seeking situation. They appeared to be realistic and personal, and they dealt with various aspects of living with chronic pain. The following examples indicate the interplay between the three contextual dimensions, how we read them in the text, and how we integrated them in a reliable interpretation.

\subsubsection{The Immediate Inter-Subjective Relationships in Which the Narratives Were Produced}

The first contextual dimension considers the dynamics of interactions. The first lines in two of the narratives expressed pain as an overwhelming experience in everyday life. The third narrative focused more on the consequences of pain, such as leaving the work place and finding oneself in an unresolved work situation. All expressed the severe limitations in their daily lives in various ways: "Frustration, hopelessness, and lack of motivation have come into my life", "I turn over in bed a lot each night, but in the end, I manage to get up in the morning", "I have become very inactive although I take a walk with my dog every day", and "I feel terrible and I am unable to work at the moment".

\subsubsection{The Collective Social Field Where the Stories Evolved}

The collective social field considers the life context, where the narrators situated their stories relative to several outside events and figures. Obviously, independence is lost when living with chronic pain, but family life, social life, and working life are also affected. In addition, mistrust by health care workers appeared to increase their burden. These issues were expressed in their own words as follows: "I blame myself for not being a good mother"; "The grief comes when I am unable to take part in previously arranged events. I become embarrassed!"; "I met the wall totally when we talked about networks. Mine is weak and I am not satisfied"; "I have few friends I can rely on. As I 
cannot drive a car any more, I have lost my freedom"; "I experience mistrust and little knowledge among health care workers"; and "My work place has not arranged any meetings with me or made contact”.

\subsubsection{The Broad Cultural Meaning System That Supports the Interpretation of the Stories}

At this level of the analysis, the focus was on deciphering the systems of cultural meaning and values in the text in order to support the interpretation of the stories. Culture affects narrative construction by providing narrators with collectively shared meaning systems, which need to be identified by interpretation [16].

From a gender perspective, it seems that the role of women is threatened by a lack of freedom, where they may fail to fulfill family roles, participate in work outside family life, or engage in social activities. In addition, they reported a lack of understanding and help from the health care system and NAV, which is the Norwegian common agency for employment, social security, and social services [17]. This burden led to a feeling of insecurity, which was expressed in the following statements: "I have to fight for everything!"; "Most difficult is the mistrust among health care workers"; "My financial situation is a great problem"; "NAV threatened me and denied me my pension because I looked too well"; and "Facebook is the only place I can be understood and feel safe".

In the following, we provide explicit examinations of the metaphors, turning points, and therapeutic writing in the three contexts.

\subsection{Metaphors}

Several metaphors were identified as important for strengthening the text such as: "I live in a pain hell", "My heart was pulled out", "My smile is a defence for my cold heart", "I have to put on a mask and pretend that nothing is wrong", "I present a façade and do not talk about feelings", and "For me, hope is like finding a key to a better situation".

\subsection{Turning Points}

Several movements of change towards adaptation were identified in the analytic process, as illustrated by the following quotations:

"By talking with the group leaders and participants the future seems brighter. This has led to inner motivation to find the driving forces in myself".

"A meaningful life is what I make out of the situation. My plan is not to give up on hope, but to seize the day and the challenges it will bring".

"I may relapse to my old pattern, but after a while, I manage to return to my new way of life".

"I have learned that my negative thoughts do not need to guide my life. Coping means a lot and every day, I hope to perform an activity that is fulfilling".

"I have gained new insights into my own life and I am able to cope with the pain in a new way. It has been tough to accept that I have chronic pain after having undergone many rounds of anger and grief, but I have now reached a point where I 
experience more happiness".

\subsection{Therapeutic Writing}

All of the narrators emphasized that therapeutic writing was a thought-provoking process that provided clarity and release; for example: "I try to say that I have no special relationship with anybody except my children. Not even myself after writing this, which is not a nice discovery, but true enough. What is left is my belief in God, which I have promised myself".

At the end, one of the participants described what she called a small detail: "Writing about myself is new to me. The result is that I have written away my negative experiences to gain a totally new view of myself and my life, so thank you for encouraging me to write".

\section{Discussion}

The aim of the present study was to explore how narrators experience the context in which their lives unfold during a CBT programme. Our main objectives were to identify movements of change in the narratives and the value of therapeutic writing. The three stories differed because they were embedded in different contextual experiences. However, they also shared a common meta-perspective related to therapeutic elements initiated by the CBT programme, such as behavioural change processes, and reconstructing the self from hopelessness to hope. Metaphors such as "heart", "hell", "mask", "façade", and "key", as well as deletions and exclamations facilitated the understanding of the motivations, values, and meaning systems that are important for constructing identity beyond written words [5]. These features expanded the expressions of the narrators because they reveal strong thoughts and feelings, which are difficult to express openly, as part of healing [2].

In our presentation of the narratives, we demonstrated how a systematic exploration of the contexts directed our understanding of different stories and identities. When exploring the inter-subjective context, our attention was directed to the way the participants situated their stories and we identified how their meaning systems led to reflections and life choices. The narrators provided insight into living with chronic pain and how this was embodied in their identity. This first context described the current situation, such as living "in hell", "my heart is pulled out", "finding a key", illustrating the tension between a passive and uncomfortable role, and exploring hope. This strengthened our understanding of the three strong women who were actively rebuilding their lives and futures despite their disabilities.

The social field was the second context considered, which provided us with an understanding of how social roles and institutions shaped the life choices of the narrators. The relevant social fields selected may have indicated that the narrators viewed them as important for their identity [15]. Their family life was greatly affected and they tried to fulfill their expected roles. They lacked an active working life and there were few possibilities for retraining. Moreover, restrictions on their social lives prevented them from 
participating in activities with their own children, arranging parties, and forming a support network. Obviously, this led to isolation, thereby preventing self-realization and strengthening the pain experience. Metaphors such as "mask" and "façade" may have reflected the loss of self. This is supported by the findings reported by Haraldseid et al. [18], who emphasized how roles and identity can change when the experience of chronic pain prevents participation in meaningful activities in society.

To understand how the narrators depicted themselves, we also considered the cultural perspective, which highlighted the struggle to attain an active and healthy life, according to the norms of society. Being modern women in their forties and belonging to a society with equal rights for health services and economic security during sickness all influenced the discontinuity in their life stories. From a gender perspective, their situation excluded them from fulfilling their roles as independent and modern women. The use of social media, specifically Facebook, appeared to be an alternative for making social contact and sharing experiences by taking a directing role themselves. Situating their stories within these contexts helped to highlight their motivations in terms of searching for an independent and active role in life.

The life stories could also be read in terms of disapproval and negotiating with the work life and health care systems. The main aim of the common agency for employment and social security is to help more people to find work and provide appropriate services and benefits [17]. Guidelines exist for "including work life" for people with limited capacities and special needs in order to prevent their sickness absence, exclusion, and withdrawal from working life [19]. However, despite the availability of services and guidelines, better financial guidance would be useful for our narrators who found themselves in uncertain situations. The narrators also appeared to represent a challenge for the standard health care system because their problems were multifaceted. Davis [20] recommended that we should treat these patients with trust because "the pain is the patient's, [and] only he or she [can] experience it and give it meaning". Experiencing uncertainty about chronic illness has been described as stressful [21], and Hummel [22] raised important concerns about the future personal and financial resources required to manage this situation. The health care system and common agency failed to play a coordinating role to discover each individual's overall situation. Thus, better cooperation between these two systems might reduce uncertainty to offer combined and better adapted solutions.

\subsection{Movements of Change and Therapeutic Writing about Contexts}

Our depiction of the narrators as active agents for change in their own rehabilitation was also emphasized in the meta-narratives related to the CBT programme, which gave the stories a sense of coherence. When considering the three contexts as a whole, we identified different movements of change and the value of group participation and therapeutic writing were emphasized. From our perspective, the personal changes in the narrators altered the characteristics that made them who they were. This appeared to affect their ability to fulfill roles and to make changes due to a sense of loss of self in order to adopt a more active and positive approach to their lives. In terms of identity, 
greater integration of body and mind is an important part of the adaptation process, which is called "relearning the world" [23].

Our findings clearly indicate that therapeutic writing led to increased awareness, and clarification of the connection between chronic pain and the factors that may increase or decrease pain. Storytelling is said to have a constructive role [24]. By telling new stories through reconstructing and revising previous stories, the narrators were offered an opportunity to link the broken threads of their lives by obtaining an increased understanding of their illness from a broader perspective [2]. Expressive writing is thought to benefit individuals by focusing on expressions and allowing avoided material to be processed and organized [5]. Furthermore, a better understanding is achieved by exploring their deepest thoughts and feelings about challenging events and life situations. Thus, expressive writing is associated with the benefits obtained by opening up to thoughts and feelings [6]. According to our study, this form of expressive writing is close to inner speech and thought processes, and it may be considered a therapeutic tool that could facilitate reflection on the life experiences of the writers [6] [7].

Due to movements of change, our narratives can be considered as two-stage narratives, which is typical for people whose life situation has changed dramatically from good health to a state of severely reduced health [16]. These changes are often referred to as tragic narratives, which are reflected in all our narratives by many losses. However, we identified what we refer to as a third-stage narrative where a movement of change towards an optimal adaptation to the life situations of the subjects occurred following the CBT programme. In agreement with other studies, the important factors associated with successful adjustment to chronic pain appeared to be related to social and cultural aspects rather than biomedical factors [25].

\subsection{Methodological Considerations}

The texts obtained in this study differ from ordinary life stories because they were placed in a different context compared with face-to-face interviews. Thus, by considering the text objectively, the impressions that might have been elicited by an interview situation did not influence our interpretations. Using the three spheres of context model [15] [16], we analysed how different contexts might give meaning to the narratives. For practical reasons, we analysed the three spheres of context as separate and distinct, although they are interrelated and their integration can provide a complementary and wider approach for understanding life stories.

We are aware that the narratives did not cover the whole complex reality of the subjects, but instead they were limited to specific aspects of being in the world. The interpretation of context is always considered selective [15]. Thus, the narrators created a context when telling their stories, but we also created new possible contexts when interpreting their stories [15]. Therefore, the challenge was to achieve a balance between the contexts mentioned in the narratives and the cultural contexts considered in our discussion. It is important to note that comparing these stories with those of other patients could enrich our understanding of the life situation of women. 
We had a limited number of narrators, which might represent a highly selective group. However, our findings are rich and varied, according to group leaders' observations in all groups, and similar to those obtained in other comparable studies [13] [18], which may strengthen our conclusions. Chronic pain is a worldwide challenge and CBT is a well-documented approach, so we consider that the present study has broad international relevance to this area of nursing.

\section{Conclusions}

In this study, we systematically explored narratives to identify how the narrators situated their stories within various contexts and to understand the experience of living with chronic pain in a modern society. The inter-subjective context directed our attention to stories highlighting the daily struggles of the subjects. How they situated their stories within a social context highlighted the role of social order in society. The cultural perspective strengthened our understanding of the women as social people, who were active in rebuilding their lives despite the many obstacles presented by chronic pain and cultural norms.

Important change processes were identified regarding adaptation. Our findings clearly indicate that therapeutic writing is helpful. Thus, in order to help this vulnerable group of people, health carers must organize care around the illness experience and its inter-subjective, social, and cultural consequences, which may provide a deeper understanding of identity and the core themes embedded in their life stories. Therapeutic writing in a CBT programme for chronic pain represents an important tool to grasp these various aspects. Further research may consider illness narratives following interventions, including therapeutic writing and movements of change.

\section{References}

[1] Dysvik, E., Sommerseth, R. and Jacobsen, F.F. (2011) Living a Meaningful Life with Chronic Pain from a Nursing Perspective, Narrative Approach to a Case Story. International Journal of Nursing Practice, 17, 36-42. https://doi.org/10.1111/j.1440-172X.2010.01903.x

[2] Squire, C., Davis, M., Esin, C., Andrews, M., Harrison, B., Hyden, L.-C., et al. (2014) What Is Narrative Research? Bloomsbury Academic, London.

[3] O’Brian, M.R. and Clark, D. (2010) Using of Unsolicited First-Person Written Illness Narratives in Research: Systematic Review. Journal of Advanced Nursing, 66, 1671-1682. https://doi.org/10.1111/j.1365-2648.2010.05349.x

[4] Kleinman, A. (1988) The Illness Narratives, Suffering, Healing \& the Human Condition. Basic Books, USA.

[5] Bolton, G. and Wright, J.K. (2004) Conclusions and Looking Forward. In: Bolton, G., Howlet, S., Largo, C. and Wright, J.K., Eds., Writing Cures: Introductory Handbook of Writing in Counselling and Psychotherapy, Brunner-Routledge, New York, 228-231.

[6] Elbow, P. (1981) Writing with Power: Techniques for Mastering the Writing Process. Oxford University Press, New York.

[7] Thompson, K. (2004) Journal Writing as a Therapeutic Tool. In: Bolton, G., Howlett, S., Lago, C. and Wright, J.K., Eds., Writing Cures: Introductory Handbook of Writing in Counselling and Psychotherapy, Brunner-Routledge, New York, 72-84. 
[8] Gourtner, E.-M., Rude, S.S. and Pennebaker, J.W. (2006) Benefits of Expressive Writing in Lowering Rumination and Depressive Symptoms. Behaviour Therapy, 37, 292-303. https://doi.org/10.1016/j.beth.2006.01.004

[9] Berg Wikander, B., Wikström, B.-M. and Elfström, T. (2012) Using Narratives to Express Bereavement: An Interview Study on Professional Female Writers That in Their Middle Age Have Lost their Mothers. Open Journal of Nursing, 2, 41-47. https://doi.org/10.4236/ojn.2012.22008

[10] Baikie, K.A. and Wilhelm, K. (2005) Emotional and Physical Health Benefits of Expressive Writing. Advances in Psychiatric Treatment, 11, 338-346. https://doi.org/10.1192/apt.11.5.338

[11] Pennebaker, J.W., Zech, E. and Rime, B. (2002) Disclosing and Sharing Emotion: Psychological, Social and Health Consequences. In: Stroebe, M., Hansson, R.O., Stroebe, W. and Schut, H., Eds., Handbook of Bereavement Research: Consequences, Coping and Care, American Psychological Association, Washington DC, 517-545.

[12] Smyth, J., True, N. and Souto, J. (2001) Effects of Writing about Traumatic Experiences: The Necessity for Narrative Structuring. Journal of Social and Clinical Psychology, 20, 161-172. https://doi.org/10.1521/jscp.20.2.161.22266

[13] Furnes, B. and Dysvik, E. (2012) Therapeutic Writing and Chronic Pain: Experiences of Therapeutic Writing in a Cognitive Behavioural Programme for People with Chronic Pain. Journal of Clinical Nursing, 21, 3372-3381. https://doi.org/10.1111/j.1365-2702.2012.04268.x

[14] Jackson, J.E. (2005) How to Narrate Chronic Pain? The Politics and Representation. In: Carr, D.B., Loeser, J.D. and Morris, D.B., Eds., Narrative, Pain and Suffering. Progress in Pain Research and Management, IASP Press, Seattle, Vol. 4, 229-242.

[15] Zilber, T.B., Tuval-Mashiach, R. and Lieblich, A. (2008) The Embedded Narrative. Navigating through Multiple Contexts. Qualitative Inquiry, 14, 1047-1069. https://doi.org/10.1177/1077800408321616

[16] Tuval-Mashiach, R. (2014) Life Stories in Context: Using the Three-Sphere Context Model to Analyze Amos's Narrative. Narrative Works, 4, 125-145.

[17] Berg, L.P. (2015) NAV. https://snl.no/NAV

[18] Haraldseid, C., Dysvik, E. and Furnes, B. (2014) The Experience of Loss in Patients Suffering from Chronic Pain Attending a Pain Management Group Based on Cognitive- Behavioral Therapy. Pain Management Nursing, 15, 12-21.

https://doi.org/10.1016/j.pmn.2012.04.004

[19] White Paper. Regjeringen. No: 29.08.16. Including Work Life. http://www.inkluderende.no/om-inkluderende-arbeidsliv/hva-er-inkluderende-arbeidsliv

[20] David, B.D. (2000) Caring for People in Pain. Routledge, London.

[21] Lazarus, R.S. and Folkman, S. (1984) Stress, Appraisal and Coping. Springer, New York.

[22] Hummel, F.I. (2009) Powerlessness. In: Larsen, P.A. and Lubkin, I.M., Eds., Chronic Illness, Impact and Intervention, 7th Edition, Jones and Bartlett, London, 255-277.

[23] Furnes, B. and Dysvik, E. (2010) Dealing with Grief Related to Loss by Death and Chronic Pain: An Integrated Theoretical Framework. Part 1. Patient Preference and Adherence, 4, 135-140. https://doi.org/10.2147/PPA.S10580

[24] Haveri, A., Airaksinen, J. and Paananen, H. (2015) Transformation of Local LeadershipNarratives on Changed Interaction. Open Journal of Leadership, 4, 117-128. https://doi.org/10.4236/ojl.2015.44011

[25] Lacerte, M. and Shah, R.V. (2002) 1. Pain Concepts, Assessment, and Medicolegal Issues. Archives of Physical Medicine and Rehabilitation, 84, S35-S38.

https://doi.org/10.1053/apmr.2003.50048 
Appendix 1. Guidelines for writing.

- It is important to be honest, open and patient when writing.

- You may from the beginning write down goals for your writing

- In the beginning you may "warm up" writing whatever you wish related to daily life

- It is irrelevant to care about correct spelling and punctuation

- It is important to write spontaneous and let the words flow freely

- It is important that you write uncensored what appears for you

- By raising questions to your self will stimulate reflection

- You may have a conversation with yourself when you are writing

- You may raise questions to yourself trying to answer these

- It is important not only to recite what it is about, but also feelings and experiences

- Try to describe details

- Writing should occur uninterrupted in a quiet place

- You are the owner of the text

- No one else should have access to the text, you decide openness in the group

- If you strive with your writing you may discuss it with the supervisors

\section{Appendix 2. Writing tasks.}

Session

Write about your present life situation

1 What does hope mean to you?

What does joy mean to you?

Describe difficult situations related to your pain problem

3 Try to describe your thoughts and feelings related to loss and grief

Try to describe how you deal with the difficult situations

Focus is here your relationship to other persons

$5 \quad$ What kind of earlier relationships exist and how has it influenced you?

What kind of present relationships exist now and what kind of meaning do they represent?

Describe your present life situation and what is important to you now

How are you prepared to meet your new life situation?

What can you do to live a meaningful life?

How does the future look like, and what kind of plans do you have? 
Submit or recommend next manuscript to SCIRP and we will provide best service for you:

Accepting pre-submission inquiries through Email, Facebook, LinkedIn, Twitter, etc.

A wide selection of journals (inclusive of 9 subjects, more than 200 journals)

Providing 24-hour high-quality service

User-friendly online submission system

Fair and swift peer-review system

Efficient typesetting and proofreading procedure

Display of the result of downloads and visits, as well as the number of cited articles

Maximum dissemination of your research work

Submit your manuscript at: http://papersubmission.scirp.org/

Or contact ojn@scirp.org 